\title{
25-Hydroxy-vitamin D level may predict presence of coronary collaterals in patients with chronic coronary total occlusion
}

\author{
Yasemin Dogan, Bahadir Sarli, Ahmet Oguz Baktir, Serkan Kurtul, Mahmut Akpek, Omer Sahin, \\ Huseyin Odabas, Engin Dondurmacı, Mehmet Ugurlu, Eyup Ozkan
}

Department of Cardiology, Kayseri Education and Research Hospital, Kayseri, Turkey

Postep Kardiol Inter 2015; 11, 3 (41): 191-196 DOI: $10.5114 /$ pwki.2015.54012

\begin{abstract}
A bstract
Introduction: Sufficient coronary collateral circulation (CCC) protects myocardial tissue against ischemia in patients with coronary chronic total occlusion (CTO). Vitamin D is a steroid hormone which has been related to increased prevalence of hypertension, left ventricular hypertrophy, heart failure, peripheral artery disease, coronary artery disease, myocardial infarction and cardiovascular mortality.

Aim: To investigate whether there is an association between serum 25-hydroxy-vitamin D levels and development of CCC in patients with coronary CTO.

Material and methods: A total of 188 patients with CTO at coronary angiography were included in this study. Vitamin D and parathyroid hormone (PTH) levels were measured on the day of coronary angiography. Development of collateral circulation was graded according to the Rentrop classification after coronary angiography. Then, patients were divided into two groups on the basis of CCC grades: group 1 included 68 (36\%) patients with poorly developed CCC, and group 2 included 120 (64\%) patients with well-developed CCC.

Results: Patients with poorly developed CCC had significantly lower serum 25-hydroxy-vitamin D levels compared to those with well-developed CCC $(20 \pm 3$ vs. $30 \pm 6 \mathrm{ng} / \mathrm{ml}, p<0.0001)$. Multivariate logistic regression analysis indicated serum 25 -hydroxyvitamin D $(25(\mathrm{OH}) \mathrm{D})(\mathrm{OR}=1.794,95 \%$ confidence interval $(\mathrm{Cl}): 1.453-2.216 ; p<0.001)$ as an independent predictor of poor collateral flow in patients with CTO.

Conclusions: Low vitamin D level is an independent predictor of poor CCC in patients with CTO.
\end{abstract}

Key words: chronic total occlusion, vitamin D, coronary collateral circulation.

\section{Introduction}

Coronary collaterals are anastomotic channels between portions of the same coronary artery or between different coronary arteries, and have long been considered as an alternative source of blood supply to the jeopardized ischemic myocardium. Presence of coronary collateral circulation (CCC) is of great importance particularly in patients with a chronic total occlusion (CTO, Figure 1). Previous studies assessing prevalence have differed with regard to the reference population. A previous study showed that the overall prevalence of CTO in patients with coronary artery disease (CAD) referred for elective coronary angiography is $18.4 \%$ [1, 2]. Collateral vessels develop from congenital intracoronary anasto- mosis following chronic ischemia or hypoxia and growth factors and inflammatory cells play a significant role in development of CCC $[3,4]$. It has been shown that wellgrown CCC has beneficial effects on infarct size, aneurysm formation and ventricular function.

Vitamin D is a kind of steroid hormone produced via sun exposure in the skin. Once consumed or made in the skin, vitamin D undergoes two hydroxylation steps to generate the final hormonal form. It is hydroxylated first in the liver to produce 25-hydroxyvitamin $\mathrm{D}_{3}\left(25(\mathrm{OH}) \mathrm{D}_{3}\right)$ and then second in the kidney to create the hormonal form, $1 \alpha, 25$-dihydroxyvitamin $\mathrm{D}_{3}\left(1,25(\mathrm{OH})_{2} \mathrm{D}_{3}\right)$. Vitamin $\mathrm{D}$ deficiency is associated with several chronic disease states including one affecting the cardiovascular system. Many studies have demonstrated that low serum 25-hy-

\section{Corresponding author:}

Prof. Bahadir Sarli MD, PhD, Department of Cardiology, Kayseri Education and Research Hospital, Hastane Cad., 38010 Kayseri, Turkey, phone: +90 5353040445, e-mail: drsarli@yahoo.com

Received: 2.03.2015, accepted: 10.05.2015. 


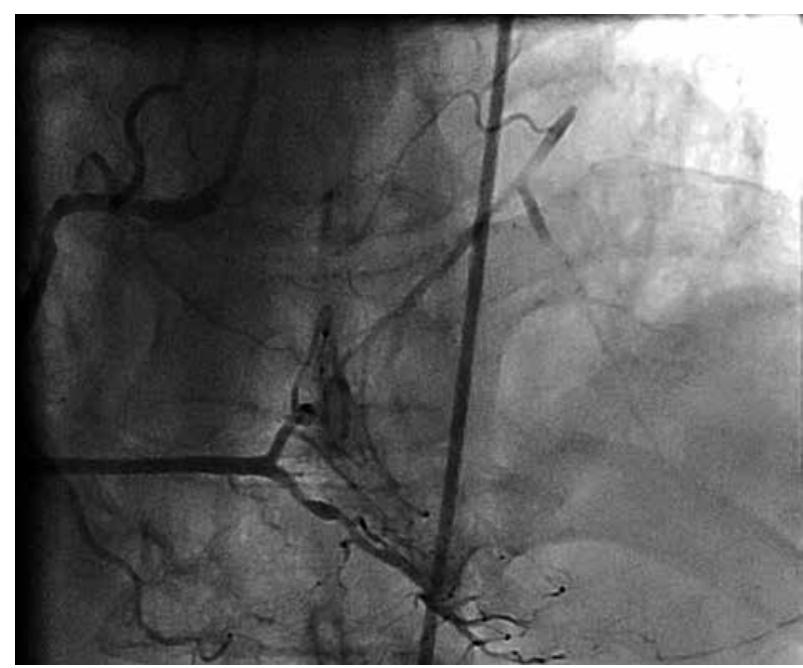

Figure 1. Figure showing a Rentrope grade 3 collateral arising from distal aspect of the right coronary artery which supplies blood to the occluded left circumflex artery

droxy D vitamin level is associated with increased prevalence of hypertension, left ventricular hypertrophy, heart failure, peripheral artery disease, coronary artery disease, myocardial infarction and cardiovascular mortality [5-10]. However, there are limited data regarding the role of vitamin D level in development of CCC in patients with CTO.

\section{Aim}

In this study, we aimed to evaluate whether there is an association between serum vitamin D level and CCC in patients with CTO.

\section{Material and methods}

\section{Study population}

A total of 173 patients with a CTO in at least one coronary artery, who were referred to our hospital for coronary angiography between March 2013 and January 2014, were included in this observational study.

Patients with a history of acute coronary syndromes within the last 3 months, chronic inflammatory disease, coronary bypass surgery, severe cardiac valvular diseases, chronic kidney disease (creatinine > $1.4 \mathrm{mg} / \mathrm{dl}$ ), chronic pulmonary disease, known malignity and those with active infection were excluded.

Risk factors for CAD including hypertension, diabetes mellitus, hyperlipidemia and smoking were recorded in all patients. Left ventricular ejection fraction (LVEF) was calculated from conventional apical 2- and 4-chamber images using biplane Simpson's technique. Following coronary angiography, patients were divided into 2 groups based on the degree of CCC development as follows: group 1, patients with poorly developed CCC (Rentrop 0, 1); and group 2, those with well-developed CCC (Rentrop 2, 3).

\section{Biochemical analysis}

Blood samples were drawn to evaluate serum 25(OH)D levels. Serum 25(OH) D levels were measured with a HPLC device using the chromatographic method (Shimadzu LC 20AD/T, Kyoto, Japan). Serum creatinine, calcium, high-density lipoprotein (HDL), low-density lipoprotein (LDL), triglyceride, total cholesterol, glucose, high-sensitivity $\mathrm{C}$ reactive protein (hs-CRP), and parathyroid hormone (PTH) levels were also measured in the blood samples drawn.

\section{Coronary angiography}

Coronary angiography was performed via femoral catheterization by the Judkins method. Patients with at least a CTO in one coronary artery were included in this study. Collateral circulation was graded according to the Rentrop classification as follows: 0, no marked collateral circulation; 1$)$ collateral circulation at lateral branches but not reaching the epicardial coronary artery; 2) partial filling of the epicardial segment through collateral channels; 3 ) presence of complete filling in the epicardial coronary artery [11].

\section{Statistical analysis}

All analyses were carried out using SPSS 15.0 for Windows (SPSS Inc., Chicago, Illinois, USA). Continuous variables were given as mean \pm standard deviation; categorical variables were defined as percentages. The variables were investigated using the Kolmogorov-Smirnov test to determine whether they are normally distributed. Independent samples $t$ test was used to compare continuous variables between the two groups. Non-parametric values were compared with the Mann-Whitney $U$ test. The $\chi^{2}$ test was used to compare categorical data. Pearson and Spearman's correlation coefficient was used to examine the association between serum 25(OH)D levels and Rentrop score. The effects of different variables on CCC were calculated using univariate analysis. The variables for which the unadjusted $p$ was $<0.10$ in logistic regression analysis were identified as potential risk markers and included in the full model. We reduced the model using backward elimination multivariate logistic regression analyses, and we eliminated potential risk markers using likelihood ratio tests. A two-tailed $p$ value $<0.05$ was considered as significant.

\section{Results}

A total of 188 patients (mean age $65 \pm 11$ years, 120 men) were included in this study. Group 1 included 68 patients with poorly developed CCC (Rentrop 0, 1) and group 2 included 120 patients with well-developed CCC (Rentrop 2, 3). Comparison of baseline characteristics of patients with poorly developed CCC and well-developed CCC are shown in Table I. Mean age, sex, body 
mass index, smoking history, ejection fraction, presence of diabetes mellitus and hypertension were similar in the two groups. The levels of fasting glucose, low-density lipoprotein cholesterol, high-density lipoprotein cholesterol, triglyceride, creatinine, calcium and white blood cell count were also similar between the two groups (Ta- ble II). However, patients with poorly developed CCC had significantly lower serum $25(\mathrm{OH}) \mathrm{D}$ levels compared to those with well-developed CCC (20 \pm 3 vs. $30 \pm 6 \mathrm{ng} / \mathrm{ml}$, $p<0.0001$, Figure 2).

Correlation analysis showed a significant correlation between vitamin $\mathrm{D}$ levels and the Rentrop score

Table I. Demographic characteristics of the study population

\begin{tabular}{|c|c|c|c|}
\hline Parameter & Poorly developed CCC $(n=68)$ & Well-developed CCC $(n=120)$ & Value of $p$ \\
\hline Age [years] & $65 \pm 12$ & $65 \pm 11$ & 0.890 \\
\hline Gender, male & $41(60 \%)$ & $79(66 \%)$ & 0.192 \\
\hline Diabetes, $n$ & $26(38 \%)$ & $42(35 \%)$ & 0.757 \\
\hline Hypertension, $n$ & $41(60 \%)$ & $76(63 \%)$ & 0.686 \\
\hline Smoking, $n$ & $30(44 \%)$ & $61(51 \%)$ & 0.178 \\
\hline $\mathrm{BMI}\left[\mathrm{kg} / \mathrm{m}^{2}\right]$ & $28 \pm 5$ & $27 \pm 5$ & 0.136 \\
\hline Ejection fraction (\%) & $41 \pm 8$ & $43 \pm 9$ & 0.473 \\
\hline \multicolumn{4}{|l|}{ Ocluded artery, $n$ (\%): } \\
\hline LAD & 11 & 41 & 0.011 \\
\hline LCX & 25 & 31 & 0.073 \\
\hline RCA & 36 & 55 & 0.340 \\
\hline \multicolumn{4}{|l|}{ Rentrop score, $n$ : } \\
\hline 0 & 9 & & \\
\hline 1 & 59 & & \\
\hline 2 & & 68 & \\
\hline 3 & & 52 & \\
\hline
\end{tabular}

$B M I$ - Body mass index, CCC - coronary collateral circulation, LAD - left anterior descending artery, LCX - left circumflex artery.

Table II. Comparison of laboratory features of patients with poorly developed and well-developed coronary collateral circulation

\begin{tabular}{|c|c|c|c|}
\hline Parameter & Poorly developed CCC $(n=68)$ & Well-developed CCC $(n=120)$ & Value of $p$ \\
\hline Fasting glucose $[\mathrm{mg} / \mathrm{dl}]$ & $128 \pm 36$ & $118 \pm 30$ & 0.145 \\
\hline Creatinine $[\mathrm{mg} / \mathrm{dl}]$ & $1.1 \pm 0.9$ & $1 \pm 0.9$ & 0.693 \\
\hline LDL cholsesterol [mg/dl] & $123 \pm 49$ & $128 \pm 46$ & 0.484 \\
\hline HDL cholesterol [mg/dl] & $40 \pm 8$ & $41 \pm 8$ & 0.859 \\
\hline Triglyceride $[\mathrm{mg} / \mathrm{dl}]$ & $201 \pm 98$ & $196 \pm 121$ & 0.826 \\
\hline $25(\mathrm{OH}) \mathrm{D}_{3}[\mathrm{ng} / \mathrm{ml}]$ & $20 \pm 3$ & $30 \pm 6$ & $<0.001$ \\
\hline $\mathrm{Ca}$ & $8.9 \pm 0.5$ & $9.2 \pm 0.5$ & 0.393 \\
\hline Leucocyte count $\left[\times 10^{3} \mu \mathrm{l}\right]$ & $8.8 \pm 0.3$ & $9.0 \pm 0.3$ & 0.684 \\
\hline Hemoglobine $[\mathrm{g} / \mathrm{dl}]$ & $14.1 \pm 3$ & $14.6 \pm 3$ & 0.328 \\
\hline Platelet count $\left[10^{3} / \mathrm{mm}^{3}\right]$ & $244 \pm 75$ & $252 \pm 76$ & 0.519 \\
\hline $\mathrm{Hs}-\mathrm{CRP}[\mathrm{mg} / \mathrm{l}]$ & $4.3 \pm 0.3$ & $3.4 \pm 0.4$ & 0.035 \\
\hline
\end{tabular}

Ca-Calcium, HDL - high density lipoprotein cholesterol, LDL - low density lipoprotein cholesterol, Hs-CRP-high sensitivity C-reactive protein. 


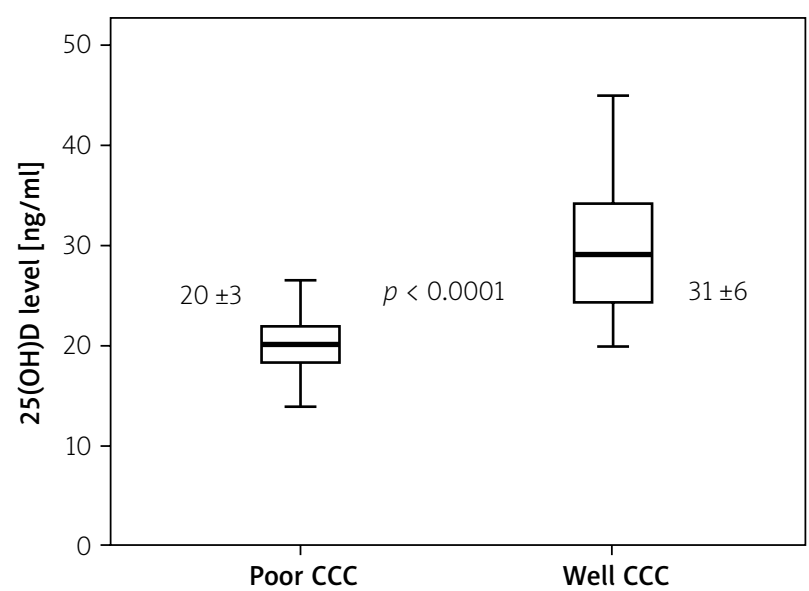

Figure 2. Comparison of $25(\mathrm{OH}) \mathrm{D}$ levels in patients with poorly developed coronary collaterals and well developed coronary collaterals

$(r=0,714$ and $p<0.001$, Figure 3). Serum 25(OH)D (OR $=$ 1.794, 95\% confidence interval: $1.453-2.216 ; p<0.001)$ and hs-CRP levels (OR $=0.910,95 \% \mathrm{Cl}$ : 0.830-0.996; $p=0.041$ ) were independent predictors of poor collateral flow in multivariate logistic regression analysis (Table III).

\section{Discussion}

The present study shows that patients with CTO and poorly developed CCC have lower serum $25(\mathrm{OH}) \mathrm{D}_{3}$ levels compared to patients with well-developed CCC. This study also shows that lower serum $25(\mathrm{OH}) \mathrm{D}_{3}$ levels may

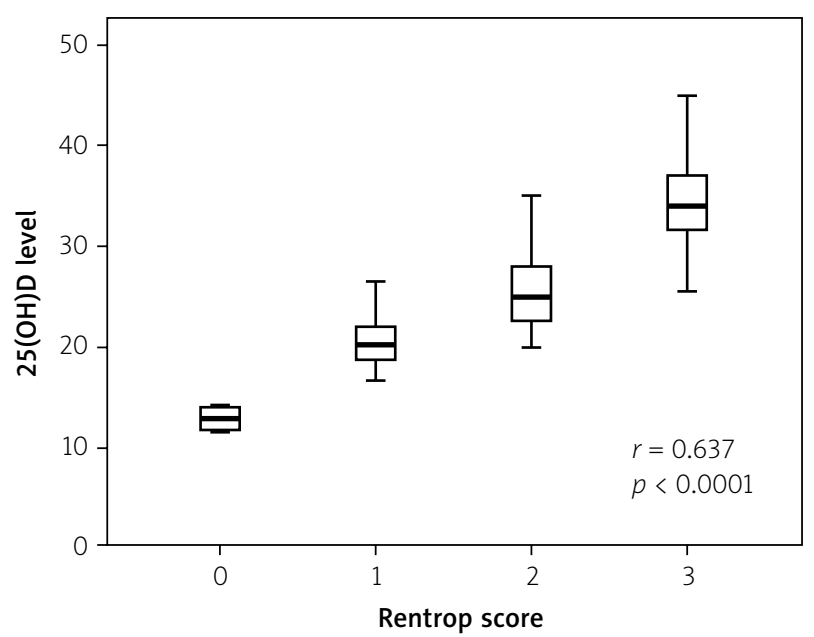

Figure 3. Relation between Rentrope Score and serum $25(\mathrm{OH}) \mathrm{D}$ levels in patients with a chronic coronary total occlusion

independently predict poorly developed CCC in patients with coronary CTO.

Development of CCC occurs through either angiogenesis of novel capillaries arising from available blood vessels or proliferation and maturation (arteriogenesis) of congenital intracoronary anastomoses following chronic ischemia or hypoxia. The main factor affecting development of collateral coronary vessels is the pressure gradient between segments localized at proximal and distal ends of the occlusion [12]. Growth factors released from endothelial cells and inflammatory cells recruited to ischemic tissue such as platelets and monocytes play a sig-

Table III. Predictors of well developed coronary collaterals in univariate and multivariate logistic regression analyses

\begin{tabular}{|c|c|c|c|c|c|c|}
\hline Variables & Unadjusted OR & $95 \% \mathrm{Cl}$ & Value of $p$ & Adjusted OR & $95 \% \mathrm{Cl}$ & Value of $p$ \\
\hline Male gender & 1.335 & $0.689-2.587$ & 0.392 & & & \\
\hline Age & 1.002 & $0.975-1.029$ & 0.889 & & & \\
\hline Diabetes & 2.197 & $1.161-4.158$ & 0.016 & 1.590 & $0.553-4.575$ & 0.389 \\
\hline Hypertension & 0.903 & $0.469-1.738$ & 0.760 & & & \\
\hline Smoking & 0.619 & $0.334-1.150$ & 0.129 & & & \\
\hline SBP & 1.000 & $0.987-1.013$ & 0.975 & & & \\
\hline BMI & 0.953 & $0.894-1.016$ & 0.139 & & & \\
\hline LAD involvement & 0.362 & $0.162-0.810$ & 0.013 & 0.553 & $0.150-2.034$ & 0.373 \\
\hline LCX involvement & 1.830 & $0.942-3.555$ & 0.074 & 2.086 & $0.608-7.154$ & 0.242 \\
\hline Vit. D level & 1.817 & $1.491-2.215$ & $<0.001$ & 1.794 & $1.453-2.216$ & $<0.001$ \\
\hline Creatinine & 0.936 & $0.674-1.300$ & 0.693 & & & \\
\hline $\mathrm{Hs}-\mathrm{CRP}$ & 0.914 & $0.867-0.963$ & 0.001 & 0.910 & $0.830-0.996$ & 0.041 \\
\hline Leucocyte count & 1.022 & $0.922-1.132$ & 0.682 & & & \\
\hline
\end{tabular}

$B M I$ - Body mass index, LAD - left anterior descending artery, LCX - left circumflex artery, SBP - systolic blood pressure, Hs-CRP - high sensitivity C-reactive protein. 
nificant role in both angiogenesis and arteriogenesis [3, 4]. A capillary-like structure forms in the early phase of collateral development, while proliferation occurs in the maturation phase by increased activity of endothelial cells and smooth muscle cells [13]. Endothelial cells have a key role in development and maturation of CCC $[14,15]$.

Many recent trials have shown that vitamin $D$ has a considerable role in development of many cardiovascular diseases. Several mechanisms including the effect of vitamin D on the renin-angiotensin system, vessel compliance, blood pressure, parathyroid hormone level and glycemic control have been implied in such a role. Moreover, it is also known that vitamin D has anti-inflammatory effects, which precludes cholesterol removal by macrophages and foam cell formation. In addition, it was found that there is an inverse relationship between serum vitamin D level and coronary artery calcification [16].

Vitamin D is involved in the pathogenesis of vascular diseases. Endothelial cells are target cells for vitamin D. It exerts its anti-atherosclerotic effects through inhibition of macrophage transformation to foam cells, down-regulation of vascular smooth muscle cell proliferation and migration, and suppression of inflammation that triggers expression of endothelial adhesion molecules. In addition, vitamin $D$ can prevent vascular calcification by inhibiting morphogenetic protein-2 expression [17-19].

In a European study that enrolled patients who underwent coronary angiography, it was found that the patients with serum $25(\mathrm{OH}) \mathrm{D}$ levels in the lowest quartile had the highest rate of mortality, which remained after adjustment for CAD risk factors [20].

In a recent study, Sahin et al. reported that low vitamin $D$ levels were associated with impaired development of CCC in patients with stable coronary artery disease. However, in that study, only $48 \%$ of subjects and in the control group $52 \%$ of subjects had a totally occluded coronary artery [21]. In our study, we enrolled only patients with a CTO, where sufficient CCC has vital importance in maintenance of myocardial function.

Although the precise mechanism underlying the association between vitamin D level and CCC remains largely unknown, some plausible explanations may be proposed. Coronary angiogenesis and collateral growth are chronic adaptive processes against myocardial ischemia, which aim to restore coronary blood flow and protect myocardium against chronic ischemia. Nitric oxide (NO), an indicator of endothelial function, plays a major role in collateral vessel development. There has been increasing evidence indicating that vitamin D deficiency is associated with an increase in the incidence and severity of immune-inflammatory disorders. Recently, Molinari et al. described beneficial effects of vitamin D on vascular functions in terms of NO production [22]. Uberti et al. reported that vitamin D can prevent endothelial cell death through modulation of the interplay between apoptosis and autophagy. This effect is achieved through inhibition of superoxide anion generation, maintained mitochondria function and cell viability, activation of survival kinases, and induction of NO production [23]. Moreover, in a study by Amer et al., it was observed that $25(\mathrm{OH}) \mathrm{D}$ level $\leq 21 \mathrm{ng} / \mathrm{ml}$ is associated with increased serum CRP level, which is a major inflammatory marker for cardiovascular risk [24]. It is well known that an elevated level of CRP is associated with increased cardiovascular risk, even in healthy people. High-sensitivity CRP attenuates nitric oxide production and inhibits angiogenesis, which may result in impaired collateral development. Together with low vitamin D levels, the hs-CRP level was found to be significantly higher in our patients with poor collateral development.

Another potential mechanism to explain the association of vitamin D levels and development of CCC is the presence of an inverse relation between physical activity and vitamin D levels. There is evidence suggesting that exercise may enhance CCC in patients with severe coronary artery disease [25]. Previously, Seiler and colleagues conducted long-term cross-sectional prospective studies using the collateral flow index (CFI) measured during percutaneous angioplasty to assess the effects of chronic increases in physical activity (determined by a structured interview) on the collateral circulation of patients with coronary disease [26]. A correct association between vitamin $D$ levels and physical activity has been reported by many investigators [27, 28]. Physical inactivity reflected by lower vitamin $D$ levels may likely play a role in the deterioration of coronary collateral flow in patients with CTO.

Collateral formation was assessed by coronary angiography in this study. Measuring collateral flow index by intravascular Doppler guidewire may provide a more objective physiological measurement of collateral grade. Also, diabetes was not found to have a relation with poor CCC in our study. As shown by Niccoli et al., better collateral development towards the culprit vessel has been observed in patients with diabetes compared to those without diabetes [29].

Although we found a correlation between low vitamin D levels and CCC, poor health status, which is closely related to vitamin $D$ deficiency, may also be associated with poor CCC development in these patients. Although we established the association of serum 25(OH)D levels and CCC angiographically, the clinical relevance of this relation is still controversial. In a previous study Meier et al. noted that visible coronary collateral vessels may even be associated with poor outcomes in patients with acute coronary syndromes [30]. Prospective studies with clinical endpoints will be able to provide answers regarding the clinical relevance of the relation of serum $25(\mathrm{OH}) \mathrm{D}$ levels and CCC. 


\section{Conclusions}

The present study shows that patients with a CTO and poor CCC have lower serum 25(OH)D levels compared to those with well-developed CCC. Our study also shows that, in patients with a CTO, low serum $25(\mathrm{OH}) \mathrm{D}$ level is an independent predictor of poor CCC. According to our results, we speculate that blunted collaterals might be a cause of poor cardiovascular outcomes in patients with CAD and vitamin D deficiency.

\section{Conflict of interest}

The authors declare no conflict of interest.

\section{References}

1. Fefer P, Knudtson ML, Cheema AN, et al. Current perspectives on coronary chronic total occlusions: the Canadian Multicenter Chronic Total Occlusions Registry. J Am Coll Cardiol 2012; 59: 991-7.

2. Christofferson RD, Lehmann KG, Martin GV, et al. Effect of chronic total coronary occlusion on treatment strategy. Am J Cardiol 2005; 95: 1088-91.

3. Van Royen N, Piek JJ, Schaper W, et al. Arteriogenesis: mechanisms and modulation of collateral artery development. J Nucl Cardiol 2001; 8: 687-93.

4. Kersten JR, Pagel PS, Chilian WM, et al. Multifactorial basis for cronary collateralization: a complex adaptive response to ischemia. Cardiovasc Res 1999; 43: 44-57.

5. Melamed ML, Muntner P, Michos ED, et al. Serum 25 hydroxyvitamin $D$ levels and the prevalence of peripheral arterial disease: results from NHANES 2001 to 2004. Arterioscler Thromb Vasc Biol 2008; 28: 1179-85.

6. Dobnig H, Pilz S, Scharnagl H, et al. Independent association of low serum 25-hydroxyvitamin D and 1,25-dihydroxyvitamin D levels with all-cause and cardiovascular mortality. Arch Intern Med 2008; 168: 1340-9.

7. Pilz S, Marz W, Wellnitz B, et al. Association of vitamin D deficiency with heart failure and sudden cardiac death in a large cross-sectional study of patients referred for coronary angiography. J Clin Endocrinol Metab 2008; 93: 3927-35.

8. Demir M, Demir C, Keçeoğlu S. The relationship between vitamin D deficiency and coronary artery ectasia. Postep Kardiol Inter 2014; 10: 238-41.

9. Burgaz A, Orsini N, Larsson SC, et al. Blood 25-hydroxyvitamin D concentration and hypertension: a meta-analysis. J Hypertens 2011; 29: 636-45.

10. Giovannucci E, Liu Y, Hollis BW, et al. 25-hydroxyvitamin D and risk of myocardial infarction. Arch Intern Med 2008; 168: 117480.

11. Rentrop KP, Thornton JC, Feit F, Van Buskirk M. Determinants and protective potential of coronary arterial collaterals as assessed by an angioplasty model. Am J Cardiol 1988; 61: 677-84.

12. Chilian WM, Mass HJ, Williams SE, et al. Microvascular occlusions promote coronary collateral growth. Am J Physiol 1990; 258: H1103-1.

13. Newman PE. The coronary collateral circulation: determinants and functional significance in ischemic heart disease. Am Heart J 1981; 102: 431-45.
14. Glasser SP, Selwyn AP, Ganz P. Atherosclerosis: risk factor and the vascular endothelium. Am Heart J 1996; 131: 379-84.

15. Schaper W, Sharma HS, Quinkler W, et al. Molecular biologic concepts of coronary anastomoses. J Am Coll Cardiol 1990; 15 : 513-8.

16. Judd S, Tangpricha V. Vitamin D deficiency and risk for cardiovascular disase. Circulation 2008; 117: 503-11.

17. Brewer LC, Michos ED, Reis JP. Vitamin D in atherosclerosis, vascular disease, and endothelial function. Curr Drug Targets 2011; 12: 54-60.

18. García-Canton C, Bosch E, Ramírez A, et al. Vascular calcification and 25-hydroxyvitamin $\mathrm{D}$ levels in non-dialysis patients with chronic kidney disease stages 4 and 5. Nephrol Dial Transplant 2011; 26: 2250-6.

19. Li X, Speer MY, Yang H, et al. Vitamin D receptor activators induce an anticalcific paracrine program in macrophages: requirement of osteopontin. Arterioscler Thromb Vasc Biol 2010; 30: 321-6.

20. Kendricka J, Targherb G, Smitsa G, et al. 25-Hydroxyvitamin D deficiency is independently associated with cardiovascular disease in the Third National Health and Nutrition Examination Survey. Atherosclerosis 2009; 205: 255-60.

21. Sahin I, Okuyan E, Gungor B, et al. Lower vitamin D level is associated with poor coronary collateral circulation. Scand Cardiovasc J 2014; 48: 278-83.

22. Molinari C, Uberti F, Grossini E, et al. 1alpha,25 dihydroxycholecalciferol induces nitric oxide production in cultured endothelial cells. Cell Physiol Biochem 2011; 27: 661-8.

23. Uberti F, Lattuada D, Morsanuto V, et al. Vitamin D protects human endothelial cells from oxidative stress through the autophagic and survival pathways. J Clin Endocrinol Metab 2014; 99 : 1367-74.

24. Amer M, Qayyum R. Relation between serum 25-hydroxyvitamin $\mathrm{D}$ and $\mathrm{C}$-reactive protein in asymptomatic adults (from the continuous National Health and Nutrition Examination Survey 2001 to 2006). Am J Cardiol 2012; 109: 226-30.

25. Laughlin $\mathrm{MH}$, Bowles DK, Duncker DJ. The coronary circulation in exercise training. Am J Physiol Heart Circ Physiol 2012; 302: 10-23.

26. Senti S, Fleisch M, Billinger $M$, et al. Long-term physical exercise and quantitatively assessed human coronary collateral circulation. J Am Coll Cardiol 1998; 32: 49-56.

27. Brock K, Cant R, Clemson L, et al. Effects of diet and exercise on plasma vitamin D (25(OH)D) levels in Vietnamese immigrant elderly in Sydney, Australia. J Steroid Biochem Mol Biol 2007; 103: 786-92.

28. Holloszy JO, Coyle EF. Adaptations of skeletal muscle to endurance exercise and their metabolic consequences. J Appl Physiol 1984; 56: 831-8.

29. Niccoli G, Giubilato S, Di Vito L, et al. Severity of coronary atherosclerosis in patients with a first acute coronary event: a diabetes paradox. Eur Heart J 2013; 34: 729-41.

30. Meier P, Lansky AJ, Fahy M, et al. The impact of the coronary collateral circulation on outcomes in patients with acute coronary syndromes: results from the ACUITY trial. Heart 2014; 100: 647-51. 